\title{
Diagnosing the Issues and Challenges in Data Integration Implementation in Public Sector
}

\author{
Noor Hasliza Mohd Hassan ${ }^{\mathrm{a} 1}$, Kamsuriah Ahmad ${ }^{\mathrm{a} 2}$, Hasimi Salehuddina ${ }^{\mathrm{a} 3}$ \\ ${ }^{a}$ Center for Software Technology and Management, Faculty of Information Science and Technology, Universiti Kebangsaan Malaysia, 43600, \\ Bangi, Selangor, Malaysia \\ E-mail: ${ }^{1}$ nhasliza948@gmail.com; ${ }^{2}$ kamsuriah@ukm.edu.my; ${ }^{3}$ hasimi@ukm.edu.my
}

\begin{abstract}
A reliable data is like the oxygen to the application systems. It keeps the application systems breathing and producing meaningful information for day to day operation and decision-making purpose in an organization. The increasing demand of reliable data in day to day operation sparks a big challenge in data integration implementation in many domains including public sector. Through a successful data integration implementation, a trustable non duplicate data will be provided to the stakeholders. Public sector as a domain which solely rely on creating value through services to the stakeholders critically in needs of reliable data to serve the reliable information to the stakeholders. However, there is lack of research being done in diagnosing the issues and challenges of data integration implementation in public sector. It is crucial to identify the issues and challenges so that we could come out with the best recommendation to ensure the feasibleness of data integration in public sector. Thus, this research had explored the issues and challenges in data integration implementation in public sector. Data has been collected using the qualitative method through the content analysis and expert interview approaches. Four main issues and challenges were identified, namely; (1) lack of management and organization support, (2) policy, standard and politics, (3) human resource incapability, and (4) lack of governance. The finding of this research enlightens the issues and challenges in data integration implementation in public sector and offers the opportunity for future work to propose the solutions to overcome the identified issues and challenges.
\end{abstract}

Keywords - issues; challenges; data integration implementation; public sector.

\section{INTRODUCTION}

Technology is rapidly evolving and stimulating the increase of data amount. Therefore, data has been described as the new gold [1]. This is due to the finding that data could transform into valuable practical information when collected and interpreted justly. Data facilitate in creating value for organization through nine factors, which among them are data source, data collection and data analysis [2]. Other than that, as information technology has become the enabler in every industry, the volume of data gathered, tabulated and published increased significantly. This also promotes the development of big data [3]. Big data, a new term used to describe sets of data that suits the criteria of: volume, velocity and variety (3Vs) [4]. It still imposed the same integration and analytical method to be efficiently translated to a meaningful information.

Quoted from Stu Higgins, Head of Smart Cities and IoT of CISCO United Kingdom and Ireland, he believed that data is not going to be useful yet valuable until it was accurately integrated and interpreted [5]. Those researches mentioned above portrayed the importance of data in the digital world today, as well as in developing digital government. The extreme increment of data production through the technology evolution has been forecasted as below:

- data stored in data centers worldwide will approximately quintuple by year 2021 to reach 1.3 zettabyte compared to 286 exabyte in year 2016; and

- data stored in devices will be roughly 4.5 times higher than data stored in data centers, at 5.9 zettabyte by year 2021 [5].

Thus, the increment of data volume and the critical need of collecting and interpreting data into useful information suggest an efficient data integration implementation to be executed. Apart from that, integrated data has been recognized for providing accurate, current and traceable information for the organizations [6]. Data integration is a process of traversing and consolidating data between storages, applications and organizations [7]. However, there is further explanation that data integration has become a discipline that blend together the art of data management and artificial intelligence [8]. Data integration discipline has grown extensively and covering many technical aspects of integration such as structured and unstructured data and providing business analytics ability. 
Hence, the importance of a reliable data integration implementation is vital to cope with the current demand. Some of the advantages of an efficient data integration has been identified as in Fig. 1[9]:

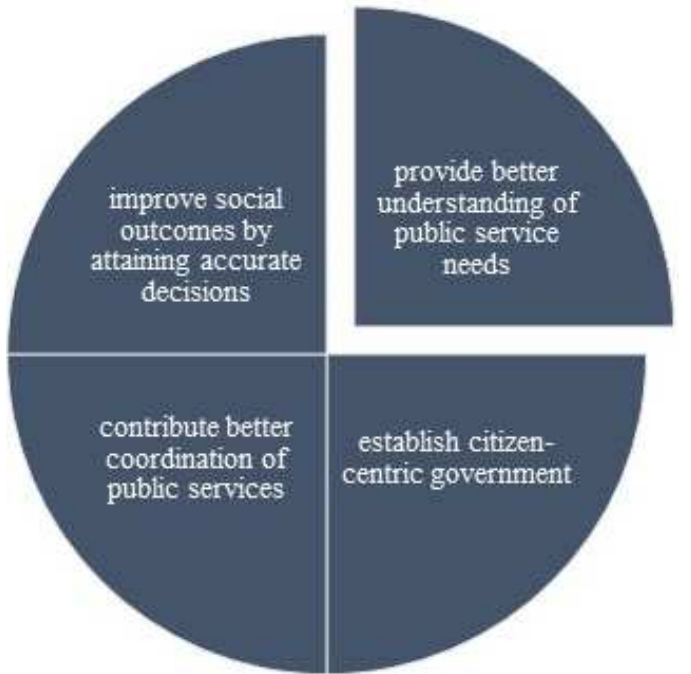

Fig.1 Efficient data integration advantages for the public sector

Other than that, through the Whole of Government (WoG) concept, one of the critical success factors towards the integrated government that has been determined is providing reliable information through "citizen centric services" [10]. Challenges in implementing data integration have become one of the hiccups not only for the private sector but also for the government to transform into "smart governments". Data integration offers a "smart service" precedent, which is a trustworthy swift service delivery to citizens, businesses and government authorities [11]. Hence, the efficient "smart service" as described by [11] in "smart government" will only be visible with a reliable data integration implementation. Building a "smart government" by providing the citizens with value added services is also one of the initiatives mention in Industrial Revolution 4.0 (IR4.0). At the same time, IR4.0 has identified data integration as one of the main agenda in enhancing and giving value add in information systems management [12]. Hence, there is no doubt that supplying reliable data through data integration will be creating more value to the government's services.

The current researches showed that most of the data integration implementation failed due to the technical and non-technical issues and challenges equally. Previous researchers found that the industry has declared the failure rate of integration projects is around $70 \%$ with the issues of such as technology, environment and management [13]. A research on Open Government Data (OGD) also supported the argument and described issues occurs in OGD implementation is similar to data integration issues which comprises the consolidation of technology-organizationenvironment issues [14]. Thus, realizing the importance of data integration implementation in public sector, this research will be carried out to find the root of the issues and challenges of data integration implementation in the public sector.

\section{MAterials AND METHOD}

\section{A. Material of Research}

Focus of this research is to find the root cause of the hiccups occurred in data integration implementation in public sector. Issues and challenges were derived from various case study in public sector across the world. Research was also expanded to similar domain which has been identified such as big data and open government data integration.

\section{B. Adaptation of Qualitative Research}

This research will be conducted using qualitative method. Qualitative research highlighted on understanding the context, which demand data collection mechanisms and tools that responsive to elemental meaning of the data [15]. In conclusion, qualitative research needs more human touch than quantitative research. Therefore, in qualitative research, "researcher is the key instrument" [16]. Hence, all the processes involved the researcher's investigation and interpretation. Data is collected through various processes such as documents analysis or content analysis, observation and interview session. In some cases of qualitative research, instrument may be used but limited to the one crafted by the researcher themselves [16].

Meanwhile, in accordance with [15], Sharan agreed that interview, observations and all types of document analysis will help the researcher to get insight on the research problem and answering the research question in qualitative study. In this study, the qualitative method will be divided into two main processes; literature review to determine the issues and challenges; and expert review for data validation. One of the approaches being identified to determine and build the theoretical framework is through the literature review [15]. Empirical data captured and examined by previous researchers is referred to, through this process.

\section{Three Phases of Research Process}

This research has been designed and conducted in three main phases as adopted from [17]. The three phases involved are; selection of document and content analysis, expert interview validation and, results and discussion as per in Fig. 2.

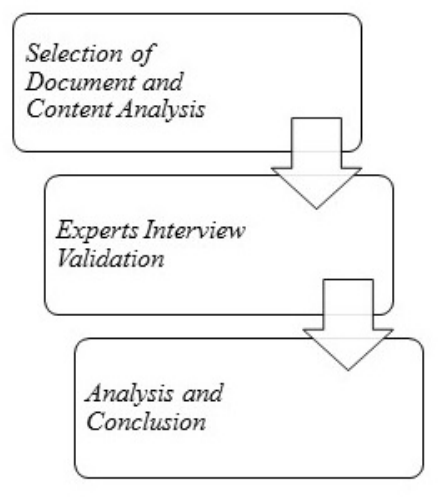

Fig. 2 The research process

1) Phase 1: Selection of Document and Content Analysis: Relevant research articles were identified in Phase 1 using the keywords recognized earlier; "issues", "challenges", "data integration" or "data sharing" or "data 
linkage" and "public sector". The theme for the research articles selection was the issues and challenges in data integration implementation in public sector. The selection process involved in the Phase 1 as per in Table 1.

TABLE I

CRITERIA OF DOCUMENT SELECTION

\begin{tabular}{|c|c|}
\hline Criteria & Details \\
\hline Search & $\begin{array}{l}\text { - Research databases: Scopus, World of Science } \\
\text { (WOS), and Science Direct } \\
\text { - Search engines: Google Scholar and Research } \\
\text { Gate } \\
\text { - Trustable websites, such as the CISCO and } \\
\text { Deloitte }\end{array}$ \\
\hline Keyword & $\begin{array}{l}\text { - "issues", "challenges", "data integration" or } \\
\text { "data sharing" or "data linkage" and "public } \\
\text { sector" }\end{array}$ \\
\hline Year & $\cdot 2009-2019$ \\
\hline Inclusion & $\begin{array}{l}\text { - Journals, conference proceedings, books, theses, } \\
\text { reports } \\
\text { - Articles in English } \\
\text { - Open access articles }\end{array}$ \\
\hline Exclusion & Articles written in other languages \\
\hline
\end{tabular}

Articles were selected from year 2009 to 2019 as to study the pattern of issues and challenges in data integration implementation in a decade period, from the electronic government to digital government era. After the articles screening process was done, content analysis was conducted to review the selected documents. It has been agreed that content analysis is the most common approach used to review the documents according to [15]. Meanwhile, content analysis is also described as a tough job for the qualitative researchers as they need to decide on how to represent the data collected during the content analysis process whether to illustrate it into the tables, matrixes or the narrative form [16].

TABLE II

EXPERTS DETAILS LIST

\begin{tabular}{|c|c|c|}
\hline Expert ID and job position & $\begin{array}{l}\text { Job category and } \\
\text { work experience }\end{array}$ & $\begin{array}{l}\text { Session } \\
\text { duration }\end{array}$ \\
\hline \multicolumn{3}{|l|}{ Agency A } \\
\hline $\begin{array}{l}\text { Expert } 1 \\
\text { Senior Assistant Principal } \\
\text { Director of Government } \\
\text { Data Exchange Team [36] }\end{array}$ & $\begin{array}{l}\text { Senior Manager - } \\
20 \text { years; } 5 \text { years of } \\
\text { experience in data } \\
\text { integration }\end{array}$ & $\begin{array}{l}50 \\
\text { minutes }\end{array}$ \\
\hline $\begin{array}{l}\text { Expert } 2 \\
\text { Senior Assistant Principal } \\
\text { Director of Government } \\
\text { Data Exchange Team [37] }\end{array}$ & $\begin{array}{l}\text { Senior manager-18 } \\
\text { years; } 4 \text { years of } \\
\text { experience in data } \\
\text { integration }\end{array}$ & $\begin{array}{l}55 \\
\text { minutes }\end{array}$ \\
\hline \multicolumn{3}{|l|}{ Agency B } \\
\hline $\begin{array}{l}\text { Expert } 3 \\
\text { Senior Assistant Director of } \\
\text { Data Management Team } \\
\text { [38] }\end{array}$ & $\begin{array}{l}\text { Operation-16 } \\
\text { years; } 7 \text { years of } \\
\text { experience in data } \\
\text { management }\end{array}$ & $\begin{array}{l}45 \\
\text { minutes }\end{array}$ \\
\hline $\begin{array}{l}\text { Expert } 4 \\
\text { Senior Assistant Director of } \\
\text { Data Management Team } \\
{[39]}\end{array}$ & $\begin{array}{l}\text { Operation-13 } \\
\text { years; } 8 \text { years of } \\
\text { experience in data } \\
\text { integration }\end{array}$ & $\begin{array}{l}40 \\
\text { minutes }\end{array}$ \\
\hline
\end{tabular}

2) Phase 2: Experts Interview Validation: A series of semi-structured interviews were organized with the determined experts from public sector to identify and verify the issues and challenges in data integration implementation from the practitioner acumen. Experts were chosen according to their expertise and experiences in data integration implementation in public sector.

Issues and challenges pre-determined from the content analysis process will be tabled out to the experts. Experts were to verify the issues and challenges sorted out from the documents and presenting their review pertaining the research question. The same approach of conducting the expert review process to verify the data in their research has been adapted by [18]-[20]. It is also suggested for the researchers to carry out a detailed interview with the public sector personnel in order to gauge and verify the accurate data regarding public sector from the real environment itself [20]. Details of the experts involved in this research are as per in Table 2.

The activities involved in this Phase 2 were:

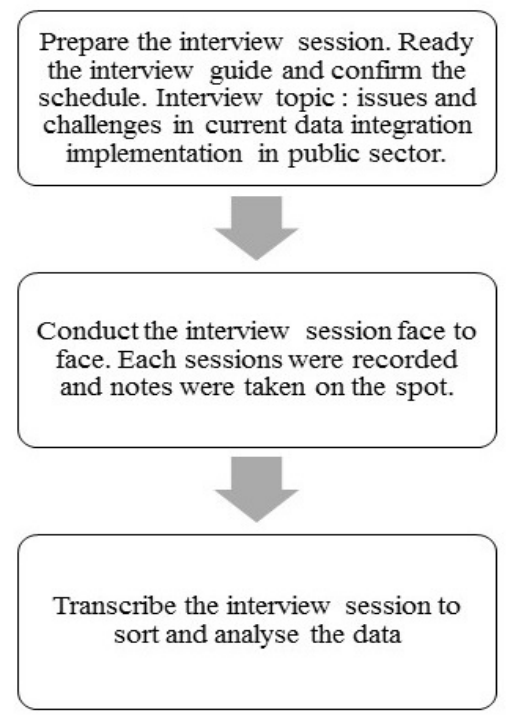

Fig. 3 Process of interview session

1) Phase 3: Analysis and Conclusion: Results from the content analysis and experts' interview were categorized, analyzed and discussed accordingly.

\section{RESULTS AND DISCUSSION}

Major issues and challenges of data integration implementation in public sector which determined from the research are summarized in Table 3. Categorization done based on the keyword found in the issues and challenges being diagnosed. We had tabulated the issues and challenges into 4 categories, which are; lack of management and organization support, policy, standard and politics, human resource incapability, and lack of governance.

Further discussions on the issues and challenges are as follows:

1) Lack of management and organization support: Management; and organizational capability and support, portray an important role in data integration implementation. Management and organizational issues such as the technology adaptability, data collection procedures and cost are among the challenges faced in data integration implementation in public sector that have being identified 
[6]. The data ownership management also being recognized by [21] as one of the challenges occurred. These findings were also supported by a discussion which concurred that issues pertaining organization's vision, mission, culture and structure, technology biasness and IT strategy also affected the implementation of data integration in public sector [22], [23]. Meanwhile, it is conferred that not only the intraorganizational issues has become the threat, interorganizational collaboration and management should be addressed too in order to successfully implementing data integration in public sector [11], [24], [25].

TABLE III

SUMMARY OF RESULTS

\begin{tabular}{|l|l|l|}
\hline $\begin{array}{l}\text { Issues and challenges in } \\
\text { data integration } \\
\text { implementation in public } \\
\text { sector }\end{array}$ & Researchers & $\begin{array}{l}\text { Interview } \\
\text { session }\end{array}$ \\
\hline $\begin{array}{l}\text { Lack of management and } \\
\text { organization support }\end{array}$ & $\begin{array}{l}{[6],[11],[21]-} \\
{[25]}\end{array}$ & $\sqrt{ } \sqrt{ }$ \\
\hline $\begin{array}{l}\text { Policy, standard and } \\
\text { politics }\end{array}$ & {$[22]-[24]$,} & $\sqrt{ } \sqrt{ }$ \\
\hline $\begin{array}{l}\text { Human resource } \\
\text { incapability }\end{array}$ & {$[26]-[31]$} & \\
\hline Lack of governance & {$[27],[21]-[24]$,} & $\sqrt{ } \sqrt{ }$ \\
& {$[6],[27],[33]-$} & $\sqrt{ } \sqrt{ }$ \\
\hline
\end{tabular}

Expert 1 and 2 from agency A stated that the management support and organizational culture on knowledge sharing are among the challenges that the government team faced during the data integration implementation [36], [37]. Expert 3 and 4 from agency B agreed on this and described as the major obstacle are the top management buy in that will drive the implementation [38], [39].

2) Policy, standard and politics: Trust is the main concern that triggers to requirement of a compelling policy, act and political supports in data integration implementation in the public sector. Requiring trust in implementing data integration inter organizational is one of the challenges that has been rectified. The assurance of privacy dan data protection are among the consideration of the users before embarking into data integration implementation [26]. It is agreed that having a "one-off" implementation policy also creates a challenge to the integration initiative as there is no sustainability plan made [27]. Hence, imposing a legislative reformation and data sharing policy to overcome the fear of data misuse, data custodian and trust issues among the users and organization have become the recommendations which had been discussed by [22]-[24], [28], [29]. In addition to having a legislative binding the implementation, [24] proposed that the government of the organization should prepare a road map or strategic plan blue print to assist the data integration implementation.

Data integration has become a critical element in IoT implementation where they need to integrate many systems that shared the same data and information [30]. In this research, they discussed on the issues of data privacy, legal approach and keeping the privacy of information bridge in IoT environment. Other than the issue of trust, privacy and embedding policy in data sharing for public sector, [24], [27] found out that having a standard to follow as a guidance in data integration is also the other challenge to resolve. This is to ensure the sustainability, maintainability and replicability or the implementation in the public sector.

Concurrently, in the exploration of issues and challenges in interlinking the OGD in the South Korea government, research revealed that the impact and utilization of policies introduced is inadequate [31]. Among the factors contributed to this are, the lack of sharing culture and incompatible policy. Other than that, the poor standardization of OGD has been revealed as one of the challenges occurred.

Expert 1 and 2 from agency A; and expert 3 and 4 from agency $\mathrm{B}$, concurred on the idea of having a strong policy and act to bind the data integration implementation as it involves sensitive issues such as data privacy and organization's policy [36]-[39]. Other than that, Expert 1,2,3 and 4 agreed that having a standard in data integration imposed in public sector will help in cutting the cost, time and resources on the implementation [36]-[39].

3) Human resource incapability: Human resource skills and competency also contributed as one the of issues and challenges in data integration implementation. Data integration team comprises from top management until the technician level should not only being equipped with technical skills but also managerial and communication skills. It is also suggested that past experiences in data integration or any IT projects will benefit the data integration team [11], [22], [32]. Lack of skills in both technical and non-technical area will become a big challenge to execute the data integration implementation.

Other than that, the involved participants must obtain adequate knowledge about data integration and knowledge sharing [23], [27]. Not only the skill and knowledge are important, but developing the culture of information sharing among the public sector personnel also is a challenge to be addressed [21], [24]. On top of that, another issues identified is the difficulty of finding the right personnel to join the data integration team [29]. This led to lack of capable resources issue in data integration implementation in public sector.

On the other perspectives, an appropriate data integration is a critical factor in getting high quality information [37]. However, there are also issues and challenges in implementing it, such as the human factor. For example, getting customers or users' feedback is an important process in successfully implementing data integration especially for big data integration. Irrelevant and untruthful feedback will always lead to bigger issues.

Conforming to all the issues above, Expert 3 from agency B stated that the issues of lack of capable personnel is not only appears in public sector team but also the vendor team that being hired to implement the data integration project in public sector [38]. Other than that Expert 1,2 and 4 agreed that some of the IT personnel in public sector relied too much on the vendor or central agency for the data integration implementation [36], [37], [39]. This become a hurdle in maintaining the implementation across organizations.

4) Lack of governance: IT governance (ITG) presents an important role in an organization in managing the IT projects. A research indicated that there were still lack of ITG knowledge in public sector organization [33]. Hence, the research urged the need to improve on ITG structures, 
processes and systems in public sector organization to ensure the accountability and reliability of IT projects including data integration implementation.

In Ontario case study, a research found out that existing improper legislative and governance have become as a barrier to data sharing implementation in Ontario government [27]. Meanwhile, it is proposed that a good governance should complement the good the technology of data integration being used [6]. On the other hand, a suggestion is made which in order to create a reference architecture in governing the data integration implementation, the Enterprise Architecture (EA) model could be referred to as a guidance [34]. Considering EA as a guide will ensure a comprehensive bottom-up governance being developed. In previous study done by [35], they also proposed of building a holistic knowledge sharing model for the public comprising the dimensions of individual, organization and technology referring to Government of Malaysia's case study.

Meanwhile, it is also conceded that governance is one the issues that holding the data integration initiatives in public sector medical sector from expanding [36]. Expert 1,2,3 and 4 agreed on there is no comprehensive governance yet in data integration area for the public sector. Based on benchmarking done by their agency on the UK, South of
Korea and Georgia public sector, there is no specific governance for data integration being introduced yet. In Malaysia, Malaysian Administrative Modernization and Management Planning unit (MAMPU) as the central agency for IT in Malaysia is yet to produce a guideline for data integration implementation in public sector [36]-[39].

5) Discussion: The underneath hiccups derived from the four main issues and challenges of data integration implementation in public sector that has been pointed out from the research were illustrated in Table 4 and wrapped in Fig.4. Among the issues compiled; policy, standards and politics has been discussed by most researches referred in this research. In many information technology initiatives, such as the previous adoption of e-government projects, the most compelling challenge apart from the technology adaptability itself was the legal framework set up. They also found out that it is important for the government to set up and enforce the act, policies and standards to secure the successfulness of the initiative [38]. The same scenario identified during the development and implementation of Web 2.0 technology. Political aspects such as the ideology, political rivalry and establishment could affect the policy decision making regarding the initiative [39].

TABLE IV

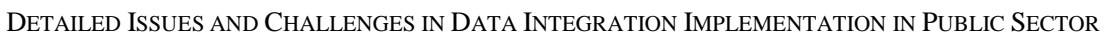

\begin{tabular}{|c|c|c|}
\hline Issues and challenges & Detailed issues and challenges & References \\
\hline $\begin{array}{l}\text { Lack of management and } \\
\text { organization support }\end{array}$ & $\begin{array}{l}\text { - poor technology adaptability } \\
\text { - data collection procedures } \\
\text { - cost } \\
\text { - poor data ownership management } \\
\text { - no alignment with the organization's vision, mission and structure } \\
\text { - technology biasness } \\
\text { - incomprehensive IT strategy } \\
\text { - poor inter-organizational collaboration }\end{array}$ & $\begin{array}{l}{[6],[11],[21]-} \\
{[25],} \\
\text { Expert [1]-[4] }\end{array}$ \\
\hline $\begin{array}{l}\text { Policy, standard and } \\
\text { politics }\end{array}$ & $\begin{array}{l}\text { - trust issues } \\
\text { - assurance of privacy dan data protection } \\
\text { - needs of legislative reformation } \\
\text { - no data sharing policy } \\
\text { - no road map or strategic plan } \\
\text { nord applied }\end{array}$ & $\begin{array}{l}\text { [22]-[24], [26]- } \\
{[31],} \\
\text { Expert [1]-[4] }\end{array}$ \\
\hline $\begin{array}{l}\text { Human resource } \\
\text { incapability }\end{array}$ & $\begin{array}{l}\text { - lack of skills and competency } \\
\text { - lack of managerial and communication skills } \\
\text { - lack of capable resources } \\
\text { - incompetence vendor } \\
\text { - customer or user unreliable feedback }\end{array}$ & $\begin{array}{l}\text { [11], [21]-[24], } \\
\text { [27], [29], [32], } \\
\text { Expert [1]-[4] }\end{array}$ \\
\hline Lack of governance & $\begin{array}{l}\text { - to improve ITG structures, processes and systems } \\
\text { - no reference architecture } \\
\text { - no holistic model of data integration governance }\end{array}$ & $\begin{array}{l}{[6],[27],[33]-} \\
{[36],} \\
\text { Expert [1]-[4] }\end{array}$ \\
\hline
\end{tabular}

Meanwhile, lack of management and organization support has become the second most significant issue and comprised the most underneath hiccups. Issues such as; no alignment with the organization's vision, mission and structure, technology biasness, incomprehensive IT strategy, poor inter-organizational collaboration, cost and data collection

The next step after diagnosing the issues and challenges is to find the dimensions and factors that best fix the issues and challenges identified. Through the research, we discover that procedures are among the challenges being picked up as mentioned in Table 4. The root cause of the lack of management and organization support issue was verified by all the Experts as the failure of getting the top management buy in and to align the business strategy with the Information Technology (IT) strategy.

the Data Governance Institution (DGI) suggests 6 focus areas in data governance which are;

- Policy, standards and strategy;

- Data quality; 
- Privacy, compliance and security;

- Architecture and integration;

- Data warehouse and business intelligence; and

- Management support.

Two of the focus areas discussed by the DGI matched the finding of this research on the issues and challenges of data integration implementation in public sector. The DGI pointed out policy, standards and strategy, and management support as among the focus areas that should be emphasized in data management regardless the activities involved including data integration [40].

For example, for the focus area of management support; The DGI proposes the activities below as in Fig. 4 to charter the management accountability in data governance:

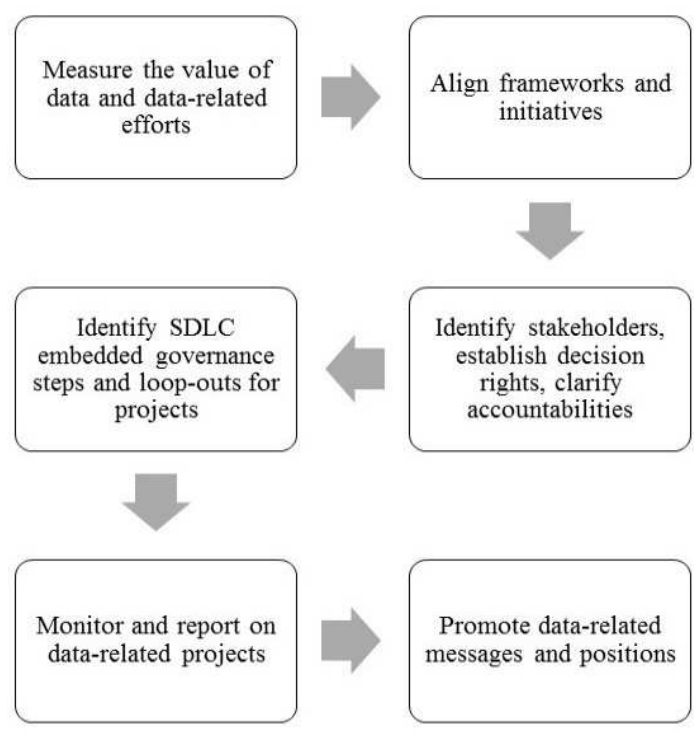

Fig. 4 Activities Proposed

The example of suggestion made by the DGI could be enhanced to suit the data integration initiatives as proposed by this research in Fig.5.

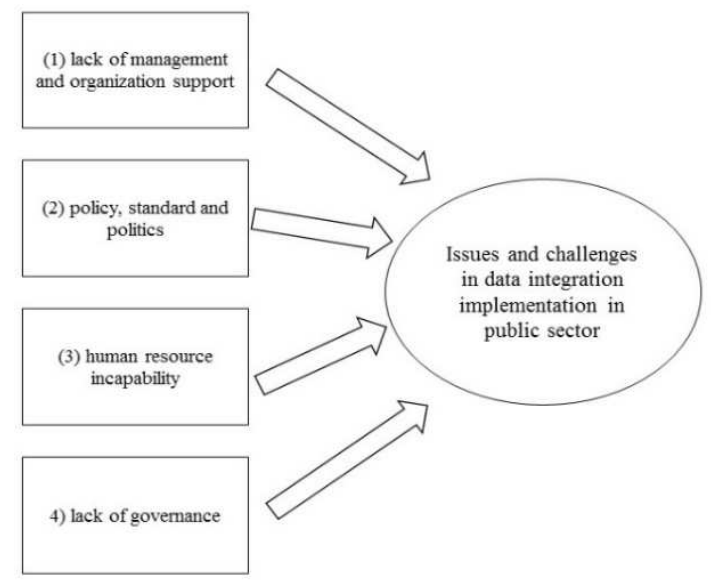

Fig. 5 Suggested activities to overcome the issues and challenges in data integration

However, further research needs to be done to identify the distinct solutions to all the issues and challenges compiled. Finding the right dimensions and factors affecting data integration, will assist in successfully implementing the data integration in public sector.

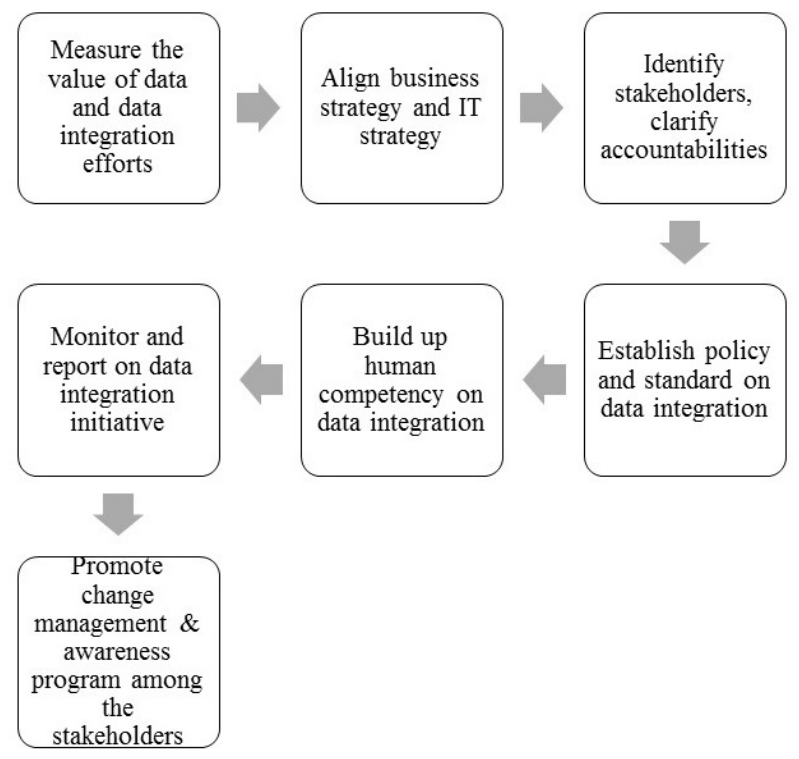

Fig. 6 Wrap up of issues and challenges in data integration implementation in public sector

\section{CONCLUSION}

This paper has contributed in diagnosing the main issues and challenges obtained in data integration implementation in public sector. It is also verified through the expert review that the issues and challenges derived from the content analysis represent the real scenario in public sector collectively. Through the content analysis and expert review processes four main issues and challenges were concluded; (1) lack of management and organization support, (2) policy, standard and politics, (3) human resource incapability, and (4) lack of governance. The four issues and challenges that have been diagnosed exhibits that apart from technology, the dimensions of management and governance represent a significant role in data integration implementation in public sector. Suggestion made in section III, subsection 5 could be used as a fundamental to further enhance the research on finding the solution. However, it is recommended for further research to first determine the severity of each issues and challenges identified in order to propose the best solutions to conquer it. Solutions for each issues and challenges could be identified by finding the right dimension and factors devoting to it.

\section{ACKNOWLEDGMENT}

This research was supported under Exploratory Research Grant Scheme ERGS/1/2013/ICT07/UKM/02/1 and PP-FTSM-2019 of National University of Malaysia (UKM) and Public Service Department (PSD) of Prime Minister's Department.

\section{REFERENCES}

[1] J. von Ditfurth and H. Aholt, "Data is the new gold: The future of real estate service providers," 2018.

[2] C. Lim, K. Kim, M. Kim, J. Heo, K. Kim, and P. P. Maglio, "From data to value: A nine-factor framework for data-based value creation 
in information-intensive services," Int. J. Inf. Manage, vol. 39, no. December 2017, pp. 121-135, 2018.

[3] D. Liu, L. Ma, X. Liu, H. Yu, and H. Tan, "Research on Key Issues of Data Integration Technology in Electric Power System in Big Data Environment," in 2017 9th IEEE International Conference on Communication Software and Network, 2017, pp. 1368-1372.

[4] R. Kitchin and G. Mcardle, "What makes Big Data, Big Data? Exploring the ontological characteristics of 26 datasets," Big Data Soc., vol. 1, no. June, pp. 1-10, 2016.

[5] CISCO, "Cisco Global Cloud Index: Forecast and Methodology, 2016-2021," 2018.

[6] D. S. Sayogo et al., "Challenges and requirements for developing data architecture supporting integration of sustainable supply chains," Inf. Technol. Manag., vol. 16, no. 1, pp. 5-18, 2015.

[7] D. International, DAMA-DMBOK2 Data Management Body of Knowledge, 2nd Editon. Technics Publications, 2017.

[8] B. Golshan, H. Alon, G. Mihaila, and W. Chiew Tan, "Data Integration: After the Teenage Years," in 2017 ACM SIGMOD/PODS Conference, 2017, pp. 101-106.

[9] A. Doan, A. Halevy, and Z. Ives, Principles of Data Integration. Morgan Kaufmann, 2012.

[10] M. H. Othman and R. Razali, "Whole of Government Critical Success Factors towards Integrated E-Government Services: A Preliminary Review," J. Pengur., vol. 53, no. 2018, pp. 73-82, 2018.

[11] M. I. Manda, "Towards 'Smart Governance' Through a Multidisciplinary Approach to E-government Integration, Interoperability and Information Sharing: A Case of the LMIP Project in South Africa," in International Conference on Electronic Government 2017, 2017, pp. 36-44.

[12] Y. Lu, "Industry 4.0: A survey on technologies, applications and open research issues," J. Ind. Inf. Integr., vol. 6, pp. 1-10, 2017.

[13] F. M. Al-balushi, M. Bahari, and A. A. Rahman, "Exploring Factors Influencing Implementation Process of Enterprise Application Integration (EAI): Lessons from Government-to-Government Project in Oman," no. October 2017, 2016.

[14] M. N. Mustapa, S. Hamid, and F. H. Nasaruddin, "Exploring the Issues of Open Government Data Implementation in Malaysian Public Sectors," vol. 9, no. 4, pp. 1466-1473, 2019.

[15] M. Sharan B. and E. J.Tisdell, Qualitative Research, 4th ed. John Wiley \& Sons Inc., 2016.

[16] J. W. Creswell and C. N. Poth, Qualitative Inquiry \& Research Design, Choosing Among Five Approaches, Fourth Edi. SAGE, 2018.

[17] W. Azlin, Z. Wan, and M. Mukhtar, Social Content Management: A Study on Issues and Challenges. Springer International Publishing, 2018

[18] W. Azlin, Z. Wan, M. Mukhtar, and Y. Yahya, "Developing the Dimensions of a Social Content Management Framework," Int. J. Adv. Sci. Eng. Inf. Technol., vol. 8, no. 5, pp. 1850-1857, 2018.

[19] L. K. W. Fernando and P. S. Haddela, "Hybrid framework for master data management," 17th Int. Conf. Adv. ICT Emerg. Reg. ICTer 2017 - Proc., pp. 142-148, 2018.

[20] A. Yasin, H. Ibrahim, M. Ahmad, M. Omar, and A. R. Othman, "A Conceptual Model of Information Sharing in E- Government Services," J. Telecommun. Electron. Comput. Eng. Establ., vol. 10, no. 1,2018 .

[21] M. A. Mohammed, E. Y. Maroof, T. Ali, and I. Huda, "What are the Electronic Information Sharing Factors that Influence the Participation Behavior in Higher Education Sector?" Procedia Procedia Comput. Sci., vol. 72, pp. 49-58, 2015.

[22] S. Eom and J. H. Kim, "Information Sharing Success in Korean Metropolitan Governments: Combining Multi-level Factors with Fuzzy-set Analysis," in Proceedings of dg.o conference, Staten Island, New York USA, June 2017 (dg.o'17), 2017, pp. 279-288.
[23] E. Maarof and H. Ibrahim, "Factors Influencing Success of Increasing Participation in Using Electronic Information Sharing between a Yemen Ministry and University," in 2017 International Conference on Research and Innovation in Information Systems (ICRIIS), 2017.

[24] Y. Akatkin and E. Yasinovskaya, "Data-Centricity as the Key Enabler of Digital Government: Is Russia Ready for Digital Transformation of Public Sector," in International Conference on Electronic Governance and Open Society: Challenges in Eurasia, 2019, pp. 439-454.

[25] D. Praditya, "Assessment of Factors Influencing Information Sharing Arrangements Using the Best-Worst Method," in Conference on $e$ Business, e-Services and e-Society I3E 2017, 2017, pp. 94-106.

[26] M. Ahmad and R. Othman, "Public Sector ICT Management Review Implementation of Electronic Government in Malaysia: The Status and Potential for Better Service to the Public," 2006.

[27] Moat KA, Wicks M, and Wilson MG, "Integrating Data Across Sectors for Public Service Improvement in Ontario," 2016.

[28] M. M. Ayyash, K. Ahmad, and D. Singh, "A hybrid information system model for trust in e-government initiative adoption in public sector organisation. Int. J. Bus. Inf. Syst., vol. 11, no. 2, pp. 162-179, 2012.

[29] F. Karlsson, M. Frostenson, F. Prenkert, E. Kolkowska, and S. Helin, "Inter-organisational information sharing in the public sector: A longitudinal case study on the reshaping of success factors," Gov. Inf. $Q .$, no. October, pp. 0-1, 2017.

[30] N. Madaan, M. Abdul, and S. M. Sastry, "Data integration in IoT ecosystem: Information linkage as a privacy threat," Comput. Law Secur. Rev. Int. J. Technol. Law Pract., vol. 34, no. 1, pp. 125-133, 2018.

[31] H. Kim, "Interlinking open government data in Korea using administrative district knowledge graph," J. Inf. Sci. Theory Pract., vol. 6, no. 1, pp. 18-30, 2018.

[32] D. S. Sayogo, J. R. Gil-garcia, F. A. Cronemberger, and B. Widagdo, "The Mediating Role of Trust for Inter-Organizational Information Sharing (IIS) Success in the Public Sector," in 18th Annual International Conference on Digital Government Research, 2017, pp. 426-435.

[33] N. Al Qassimi and L. Rusu, "IT Governance in a Public Organization in a Developing Country: A Case Study of a Governmental Organization," Procedia Comput. Sci., vol. 64, pp. 450-456, 2015.

[34] A. F. F. C. e Vasconcelos and T. J. G. Brás, "Information Reference Architecture for the Portuguese Health Sector," in 2015 IEEE 17th Conference on Business Informatics Information, 2015.

[35] Z. M.Yusof, M. B. Ismail, K. Ahmad, and M. M.Yusof, "Knowledge sharing in the public sector in Malaysia : a proposed holistic model," Inf. Dev., vol. 28, no. 1, pp. 43-54, 2012

[36] F. Prasser, O. Kohlbacher, U. Mansmann, B. Bauer, and K. Kuhn, "Data Integration for Future Medicine (DIFUTURE)," 2018.

[37] L. Dalla and R. Kenett, "Social media big data integration: A new approach based on calibration," Expert Syst. Appl., vol. 111, pp. 7690, 2018.

[38] E. Abu-Shanab and I. Shehabat, "The influence of knowledge management practices on e-government success: A proposed framework tested," Transform. Gov. People, Process Policy, vol. 12, no. 3-4, pp. 286-308, 2018.

[39] M. Pedro and R. Bolívar, "The influence of political factors in policymakers' perceptions on the implementation of Web 2. 0 technologies for citizen participation and knowledge sharing in public sector delivery," Inf. Polity, vol. 20, pp. 199-220, 2015.

[40] G. Thomas, "The DGI Data Governance Framework," 2019. 